\title{
BMJ Open Tibial nerve decompression for the prevention of the diabetic foot: a cost- utility analysis using Markov model simulations
}

\author{
Samuel Sarmiento, ${ }^{\oplus}$ James A Pierre $\mathrm{Jr},{ }^{\oplus 2}$ A Lee Dellon, ${ }^{1}$ Kevin D Frick ${ }^{3}$
}

To cite: Sarmiento S, Pierre Jr JA, Dellon AL, et al. Tibial nerve decompression for the prevention of the diabetic foot: a cost-utility analysis using Markov model simulations. BMJ Open 2019;9:e024816. doi:10.1136/ bmjopen-2018-024816

- Prepublication history for this paper is available online. To view these files, please visit the journal online (http://dx.doi org/10.1136/bmjopen-2018024816).

This abstract was presented at the Plastic Surgery Research Council 63rd Annual Meeting in Birmingham, Alabama, in May 2018.

Received 14 June 2018 Revised 18 0ctober 2018 Accepted 3 December 2018

Check for updates

(c) Author(s) (or their employer(s)) 2019. Re-use permitted under CC BY-NC. No commercial re-use. See rights and permissions. Published by BMJ.

${ }^{1}$ Department of Plastic and Reconstructive Surgery, Johns Hopkins University School of Medicine, Baltimore, Maryland, USA

${ }^{2}$ Department of Anesthesiology, University of Texas Health Science Center at Houston, Houston, Texas, USA

${ }^{3}$ Johns Hopkins University Carey Business School, Baltimore, Maryland, USA

Correspondence to

Dr Kevin D Frick; kfrick@jhu.edu

\section{ABSTRACT}

Objective To determine whether tibial neurolysis performed as a surgical intervention for patients with diabetic neuropathy and superimposed tibial nerve compression in the prevention of the diabetic foot is cost-effective when compared with the current prevention programme.

Design A baseline analysis was built on a 5-year model to determine the cumulative incidence of foot ulcers and amputations with each strategy. Subsequently, a costeffectiveness analysis and cohort-level Markov simulations were conducted with a model composed of 206 -month cycles. A sensitivity analysis was also performed.

Setting A Markov model was used to simulate the effects of standard prevention compared with tibial neurolysis on the long-term costs associated with foot ulcers and amputations. This model included eight health states.

Participants Each cohort includes simulated patients with diabetic neuropathy at different levels of risk of developing foot ulcers and amputations.

Primary and secondary outcome measures The primary outcome was the long-term trends concerning the development of ulcers and amputations with each strategy. The secondary outcome measures were quality adjusted life years (QALYs), incremental cost-effectiveness and net monetary benefits of the optimal strategy.

Results When compared with standard prevention, for a patient population of 10000 , surgery prevented a simulated total of 1447 ulcers and 409 amputations over a period of 5 years. In a subsequent analysis that consisted of 20 6-month cycles (10 years), the incremental cost of tibial neurolysis compared with current prevention was $\$ 12$ 772.28; the incremental effectiveness was 0.41 QALYs and the incremental cost-effectiveness ratio was $\$ 31330.78$. Survival was $73 \%$ for those receiving medical prevention compared with 95\% for those undergoing surgery.

Conclusion These results suggest that among patients with diabetic neuropathy and superimposed nerve compression, surgery is more effective at preventing serious comorbidities and is associated with a higher survival over time. It also generated greater long-term economic benefits.

\section{INTRODUCTION}

Due to the increasing incidence and prevalence of diabetes, a greater portion of

\section{Strengths and limitations of this study}

- This is a comprehensive simulation that includes all possible health states that could be experienced by patients with diabetic neuropathy in the lower extremity.

- As opposed to a simple simulation, a Markov model allows us to take into account events that recur over time. Therefore, we can better estimate the probability of returning to or remaining in the 'no foot ulcer' state after each intervention.

- The cost-effectiveness analysis makes it easier to understand the potential economic benefits of adopting the ideal strategy.

- As with any simulation, certain assumptions are made which may affect the results.

- The model was limited to only 5 years for the baseline simulations and 10 years for the cohort-level simulations. Additionally, it did not follow the patients until they were all deceased.

healthcare expenditures is devoted to conditions associated with the disease. In 2014, the total costs of diabetes in the USA was $\$ 245$ billion. ${ }^{1}$ This tally included $\$ 176$ billion in direct costs such as hospital services, physician fees, lab tests and the daily management of diabetes, and $\$ 69$ billion associated with disability, premature mortality and work loss. ${ }^{1}$ Additionally, according to the WHO, the total healthcare costs for an individual with diabetes is between two and three times higher than for one without the disease. ${ }^{23}$

According to the Centers for Disease Control, about a third of people aged above 40 years with diabetes have impaired sensation in the feet. ${ }^{14}$ Diabetic peripheral neuropathy can be extremely painful and debilitating to patients. The lack of sensation predisposes patients to inadvertent injury, leading to infection, ulceration and amputation. ${ }^{4}$ Neuropathy results, also, in impaired proprioception, leading to altered balance, increasing the risk of falls, with 
their associated hip and wrist fractures. Research has shown that almost $15 \%$ of people with diabetes develop at least one foot ulcer and that $60 \%-70 \%$ of diabetic foot ulcers are neuropathic in origin. In addition, about $15 \%$ of all diabetics will need a foot amputation and 20\%-25\% even require re-amputations. ${ }^{5}$ About $10 \%-25 \%$ of diabetics with neuropathy have pain, leading to the need for costly neuropathic pain medication and pain management services. Foot ulcers can also result in cellulitis and osteomyelitis requiring inpatient hospitalisation. ${ }^{5}$

A study done by Gordois $e t a l,{ }^{6}$ in which all costs were estimated in 2001 US dollars, showed that foot ulcers and amputations secondary to complications of diabetes cost US healthcare payers $\$ 11$ billion ( $\$ 15.96$ billion in 2017 US dollars). Long-term costs are especially high for those individuals that have undergone an amputation for they require extended home care and social services. ${ }^{7}$

A surgical 'prevention' approach can offer a new concept for the management of patients with diabetic neuropathy and superimposed nerve compression. ${ }^{8} 9$ The goal of this programme is to identify the presence of lower extremity nerve entrapment(s) in the diabetic population whose symptoms are progressing despite appropriate medical management. ${ }^{8} 1011$ Chronic nerve compression is likely to be present in up to $60 \%$ of this population. ${ }^{8}$ In this approach, these nerve compressions are corrected in approximately 2 hours, after which the patient walks immediately with a walker. Following the procedure, a 3-week to 6-week water therapy rehabilitation period is required. ${ }^{8}$ Implications from this surgical management programme in terms of cost-benefit analysis are available from a multicentre, prospective study that examined outcomes on 628 patients and 839 operated limbs. ${ }^{12}$ In this study, the authors ensured that each of the 38 surgeons that performed the procedure used the same operative technique. Average pain was reduced from a level of 8 out of 10 to a level of 2.5 out of $10, \mathrm{p}<0.001$. While cost reduction for pain medication was not documented in that study, it is implicit in the pain reduction results. After 3 years of observation, new ulcerations occurred in only $2(0.2 \%)$ of 782 limbs and amputations occurred in only $1(0.2 \%)$ of 839 at risk limbs. Finally, admission to the hospital for foot infections was noted to be only be $0.6 \%$ (expected was $4 \%)^{12}$

Health economic studies have indicated substantial costs associated with foot ulcers and amputations in both the short and long run. Therefore, the aim of this study was to analyse the incremental cost-effectiveness of a surgical management programme for diabetics with neuropathy and superimposed nerve compression, compared with the current medical prevention programme as per the policy of the Centers for Medicare and Medicaid Services (CMS). ${ }^{13}$ We also examined whether the additional costs associated with tibial neurolysis would be offset by reduced costs of future foot ulcers and lower extremity amputations.
Table 1 Risk groups for developing foot ulcers among patients with diabetes per the International Working Group on the Diabetic Foot

\begin{tabular}{lll}
\hline Risk group & Characteristics & $\begin{array}{l}\text { Suitability for } \\
\text { surgery }\end{array}$ \\
\hline 1 Low risk & $\begin{array}{l}\text { Diabetes but no other } \\
\text { specific risk factors for } \\
\text { foot ulcers }\end{array}$ & $\begin{array}{l}\text { Not unless } \\
\text { symptoms } \\
\text { develop or positive } \\
\text { neurosensory } \\
\text { testing }\end{array}$ \\
\hline 2 At risk & $\begin{array}{l}\text { Diabetes plus sensory } \\
\text { neuropathy identified } \\
\text { by symptoms and } \\
\text { neurosensory testing }\end{array}$ & Ideal candidates \\
\hline Increased & $\begin{array}{l}\text { Diabetes complicated } \\
\text { by sensory neuropathy } \\
\text { and peripheral vascular } \\
\text { disease and/or foot } \\
\text { deformity }\end{array}$ & Poor candidates \\
\hline 4 High risk & $\begin{array}{l}\text { Patients with diabetes at } \\
\text { least one previous foot } \\
\text { ulcer or amputation }\end{array}$ & $\begin{array}{l}\text { Potential } \\
\text { candidates if a } \\
\text { positive Tinel sign } \\
\text { is present }\end{array}$ \\
\hline
\end{tabular}

\section{MATERIALS AND METHODS \\ Description of reference population}

Data from a population-based survey of 1677 patients with diabetes in Sweden were used as a representative reference patient population from which we obtained transition probabilities for health states and risk groups. ${ }^{14}$ The mean age of this sample was 66 years with a range from 24 to 97 years. This study uses four mutually exclusive risk groups for developing foot ulcers defined according to the International Consensus on the Diabetic Foot. ${ }^{15} 16$ This risk classification is summarised in table 1. Patients in risk group 2 are considered ideal candidates for surgery. Patients in risk group 3 would not be suitable surgical candidates because of vascular compromise. However, patients in risk group 4 - those with a history of previous ulcer or toe amputation-would still be surgical candidates if the individual patient had a positive Tinel sign.

\section{Model structure and characteristics}

Our model included eight possible health states: no ulcer; three foot-ulcer states (uncomplicated foot ulcer, deep foot infection, and foot ulcer and critical ischaemia); three outcome states (primary healed, minor amputation and major amputation) and death. ${ }^{17}$ Cumulative outcome distribution of the baseline cohort $(n=10000)$ was based on 5-year simulations.

Our cohort-level analyses were based on a 10-year model consisting of 20 cycles with a duration of 6 months each. This cycle length was chosen because the average time period for ulcer healing is 6 months. The two strategies used in this model were (1) the current medical prevention strategy per the CMS and (2) a surgical strategy using tibial neurolysis. The model used can be seen in figure 1 . 


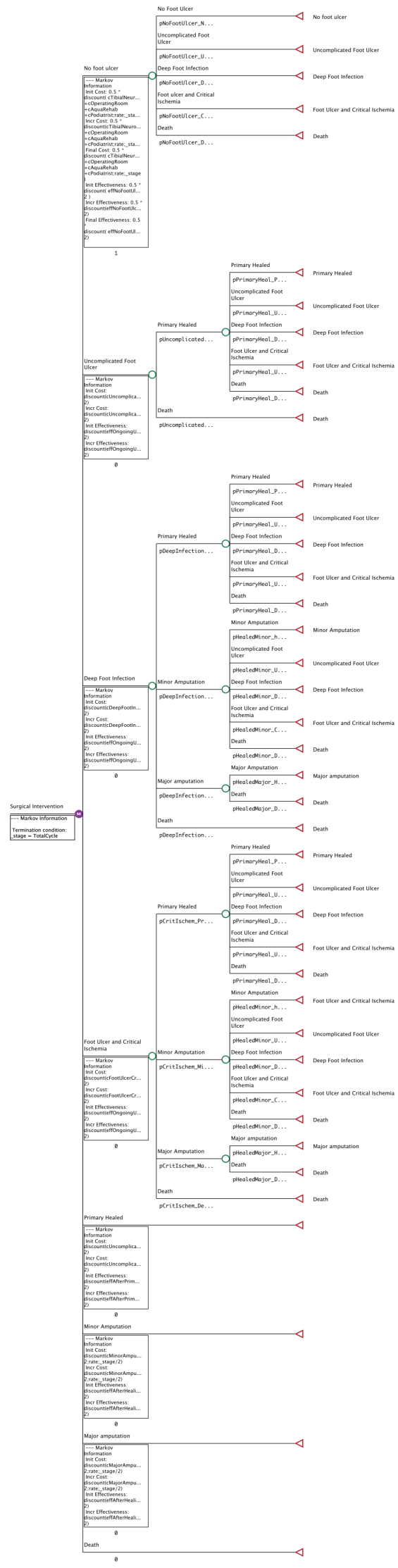

Figure 1 Model structure showing the different health states that patients are expected to transition between. While only the surgical intervention branch is shown, the medical intervention branch is identical.
Transition probabilities for health states and risk groups were garnered from the Ragnarson-Tennvall and Apelqvist article. ${ }^{14}$ Per this article, the distribution of the 1677 patients with diabetes from the reference population into the previously described four risk groups was as follows: $42.3 \%$ for risk group 1, $15.1 \%$ for risk group 2 , $28 \%$ for risk group 3 , and $14.6 \%$ for risk group 4 . In addition, the yearly incidence of foot ulcer or amputation in the reference population was $0.3 \%$ for risk group 1, 7.2\% for risk groups 2 and 3 , and $34 \%$ for risk group $4 .^{14}$

Markov cohort-level simulations were performed for the four risk groups. Each simulation represented the trajectory of a cohort of 10000 simulated Swedish patients, aged 24 years and older, with diabetes. ${ }^{14}$ In each simulation, the present level of prevention as per the CMS policy manual for each risk group was compared with the surgical intervention strategy. ${ }^{13} 1819$ The main outcome measures that were examined included the following: cumulative incidence of foot ulcers, amputations and deaths after 5 years of prevention; expected 10-year costs after current prevention versus surgical intervention; and incremental cost-effectiveness and quality-adjusted life years (QALYs) gained with the optimal prevention strategy. TreeAge Pro 2017 (TreeAge Software, Williamstown, MA, USA) was used for all simulations and cost-effectiveness calculations.

\section{Interventions}

In the baseline analysis of the current prevention strategy, it was assumed that patients from risk group 1 would receive patient education about diabetic foot care and an examination from their primary care physician (CPT code 99213) once a year. Patients from risk groups 2-4 would receive an increased level of care (HCPCS codes G0245 and G0246). ${ }^{13} 1920$ These benefits are available to qualifying Medicare patients every 6 months as stipulated by the Medicare Benefit Policy Manual (Chapter 15, Section 140). ${ }^{13}$ In addition, patients in risk groups 2-4 would be able to receive one pair of depth-inlay shoes and three pairs of inserts per calendar year as stipulated by Medicare guidelines. ${ }^{18}$

In the baseline analysis of the surgical intervention strategy, it was also assumed that patients would receive patient education about foot care from their physician. Patients would undergo the neurolysis procedure (CPT codes 64712, 64704 and 28035), estimated to require 2 hours of operating room time $(\$ 17.50$ per minute for $120 \mathrm{~min}),{ }^{21}$ and two sessions of aquatic rehabilitation therapy per week for 4 weeks postsurgery (CPT 97113).

The analysis included scenarios in which the predicted percentage of reductions in unwanted outcomes, as a result of patients undergoing the tibial neurolysis procedure, varied. This was done in order to determine if with fewer reductions in unwanted outcomes (more foot ulcers and lower extremity amputations) there would still be cost savings generated via the surgical intervention strategy and how many patients would be saved from undergoing an amputation, developing an ulcer or dying. 
These scenarios were conducted with a $3 \%$ discount rate of both costs and utilities with reductions for the surgical intervention of $60 \%, 40 \%$ and $25 \%$ compared with a baseline predicted reduction of $80 \%$. For the analysis, patients in the subcategories of uncomplicated ulcer, deep foot infection, foot ulcer and critical ischaemia, and primary healing were all considered as having had an ulcer.

\section{Costs}

Costs of the prevention and treatment strategies were obtained from the literature and the CMS Physician Fee Schedule national payment values for the 2016 calendar year. ${ }^{22}{ }^{23}$ The costs included were inflated to 2017 US values using the US Department of Labor Bureau of Labor Statistics Consumer Price Index Inflation calculator and were discounted by $3 \%$ in the baseline analysis and $5 \%$ in the sensitivity analysis to convert future costs and health effects into present value. ${ }^{24}$

Costs of the two prevention strategies were assigned to health states without current ulcer treatment. However, in the minor amputation state, both costs to prevent a new ulceration and amputation plus costs for home care, neuropathic pain medication, and social services due to amputation were included. The major amputation state included all these costs plus that of prostheses and inpatient and outpatient costs associated with the amputation.

Additionally, half cycle correction was used for costs and health effects in the model to balance the overestimation or underestimation of the cohort size when counting either at the beginning or the end of a cycle. Furthermore, treatment duration for uncomplicated foot ulceration was estimated to be 2 weeks while a deep foot infection was estimated to require 3 weeks of treatment. ${ }^{25}$ Foot ulcer and critical ischaemia were estimated to need a 6 -week course of treatment. ${ }^{25}$

\section{Quality of life}

The effectiveness measures (QALYs) were gathered from previously published studies. Based on the EuroQol instrument, it was determined that the QALYs associated with the different health states examined were as follows: 0.80 for patients with no foot ulcer, 0.44 for those with ongoing ulcer, 0.60 after primary healing of the foot ulcer, 0.61 after healing with minor amputation and 0.31 after healing with major amputation. ${ }^{26} 27$ These values were also discounted by $3 \%$ in the baseline analysis and $5 \%$ in the sensitivity analysis.

\section{Sensitivity analysis}

As part of the sensitivity analysis, the level of effectiveness of the surgical intervention was changed to $60 \%, 40 \%$ and $25 \%$ compared with a baseline predicted reduction - or effectiveness - of $80 \%$. This level was chosen because of previous research showing a clinical effectiveness of nerve decompression in the lower extremity of $80 \%{ }^{8}$

Monte Carlo techniques were also used to assess the impact of introducing stochastic elements into the analysis. Discrete event simulations and a probabilistic sensitivity analysis (PSA) were used to calculate an expected value (EV) for each strategy being compared. By sampling a representative distribution of paths through our model's chance events, this type of simulation allowed us to approximate EV calculations.

Monte Carlo techniques were also used to assess the impact of introducing stochastic elements into the analysis. Discrete event simulations and a probabilistic sensitivity analysis (PSA) were used to calculate an expected value (EV) for each strategy being compared. By sampling a representative distribution of paths through our model's chance events, this type of simulation allowed us to approximate EV calculations.

\section{Patient and public involvement}

The development of the research question and outcome measures was informed by the high prevalence of diabetes and in particular, diabetic neuropathy. To date, medical management alone does not seem to be an effective method of preventing complications related to diabetic neuropathy such as ulcers and amputations. ${ }^{4-6} 1314$ In contrast, a surgical approach involving decompression for those with diabetic neuropathy and superimposed nerve compression in the lower extremity seems promising. ${ }^{8-10} 12$ Therefore, we sought to investigate whether surgery for diabetic neuropathy was a superior strategy in the management of patients with diabetic neuropathy in the lower extremity.

This study involves health economics modelling and therefore, patients were not directly involved. However, the probabilities used are derived from the best available epidemiological data published in previous research. ${ }^{14} 17$ With this in mind, this study seeks to add to body of knowledge in this field by estimating the impact of a surgical strategy for patients with diabetic neuropathy worldwide. The results, we hope, will be readily available to patients who search for literature concerning the options available for the management of their condition.

\section{RESULTS}

\section{Baseline cohort simulations}

The results of a 5-year simulation for a cohort of 10000 patients to obtain the cumulative incidence of ulcers and amputations at a baseline reduction of $80 \%$ are summarised in table 2. Of particular interest was the considerable difference in the number of ulcers and amputations between the two prevention strategies. Among the ideal candidates for tibial neurolysis (risk group 2), assuming an $80 \%$ reduction of complications, a simulated 1447 ulcers and 409 amputations were prevented by this strategy over a period of 5 years. If surgery were to provide only a $25 \%$ reduction of complications, it would still hypothetically avert 274 ulcers and 174 amputations for patients in risk group 2.

In this simulation, as the percentage of reduction in unwanted outcomes predicted by the surgical intervention procedure decreased $(60 \%, 40 \%$ and $25 \%)$, more 
Table 2 Baseline cohort simulation results comparing the incidence of foot ulcers over 5 years by risk group between the two strategies at $80 \%$

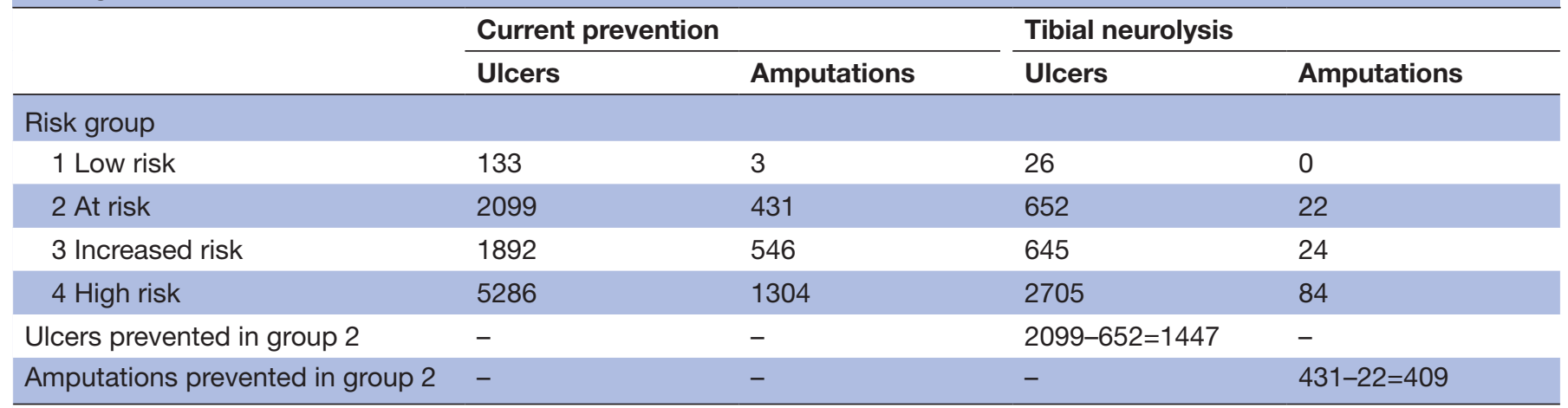

The total number of ulcers and amputations that would be prevented by surgery in group two is shown.

Cohort $n=10000$.

individuals developed foot ulcerations, underwent amputations or died when compared with the baseline scenario with a predicted reduction of $80 \%$.

\section{Cost-effectiveness analysis}

In an analysis that consisted of 20 6-month cycles (10 years), the incremental cost of tibial neurolysis compared with current prevention was $\$ 12772.28$. The QALYs were 6.30 for tibial neurolysis versus 5.90 for current prevention, with an incremental effectiveness of 0.41 QALYs. The incremental cost-effectiveness ratio (ICER) was $\$ 31330.78$ for surgery (table 3). However, the current prevention strategy is not dominated because surgery, while more effective in terms of QALYs gained, is the most costliest option.

A net monetary benefits (NMB) calculation revealed considerable gains with the surgical strategy over a period of 10 years. At a willingness-to-pay of $\$ 100,000$, the NMB was $\$ 566,766.25$ for the current prevention compared with $\$ 594,759.88$ for surgery.

\section{Markov probability analysis}

A Markov probability analysis was also conducted. Over the 10-year period of the analysis (20 6-month stages), there were important differences between the two strategies. Across all simulation stages, there was a considerably higher probability of preventing foot ulcers in the surgical intervention strategy compared with the present prevention. Conversely, amputations and mortality were lower for patients undergoing surgery. These trends can be seen in figure 2. The survival estimate was $73 \%$ for those receiving medical prevention compared with $95 \%$ for those undergoing surgery (figure 2).

\section{Sensitivity analysis}

A sensitivity analysis was conducted to assess the uncertainty of the baseline results. This type of deterministic analysis allows us to examine the extent to which our model's calculations and recommendations are affected as a result of changing selected assumptions. One such assumption tested was the annual discount rate. Under the same conditions as the baseline analysis but with a new discount rate for rewards of $5 \%$, surgery was still more effective. However, the new discount rate revealed reductions in incremental cost and effectiveness, with a lower ICER of $\$ 30020.07$.

A one-way sensitivity analysis was also performed to demonstrate how the effectiveness of preventing a foot ulcer influences the cost of the surgical intervention. At lower effectiveness rates, the present prevention strategy generated more economic benefits. However, with the trend observed, as effectiveness increases, the surgical strategy yields greater monetary benefits beginning at an effectiveness of $67 \%$.

A Monte Carlo discrete event simulation was also performed The results obtained were similar to those from our previous deterministic analyses. The long-run averaging of a microsimulation with 1000 random 'walks' and a PSA with 1000 samples showed that surgery was more effective and generated a higher median NMB compared with the current prevention strategy. These results can be seen in table 4 .

Table 3 Cost-effectiveness rankings

\begin{tabular}{|c|c|c|c|c|c|c|}
\hline Strategy & Cost (\$) & $\begin{array}{l}\text { Incremental } \\
\text { cost (\$) }\end{array}$ & Effect (QALY) & $\begin{array}{l}\text { Incremental } \\
\text { effect (QALY) }\end{array}$ & ICER (\$/QALY) & $\begin{array}{l}\text { Net monetary } \\
\text { benefit }\end{array}$ \\
\hline Current prevention & 22751.27 & & 5.90 & & & $566,766.25$ \\
\hline
\end{tabular}

Costs in US\$. Net monetary benefit uses a willingness-to-pay of $\$ 100000$.

ICER, incremental cost-effectiveness ratio; QALY, quality-adjusted life years . 

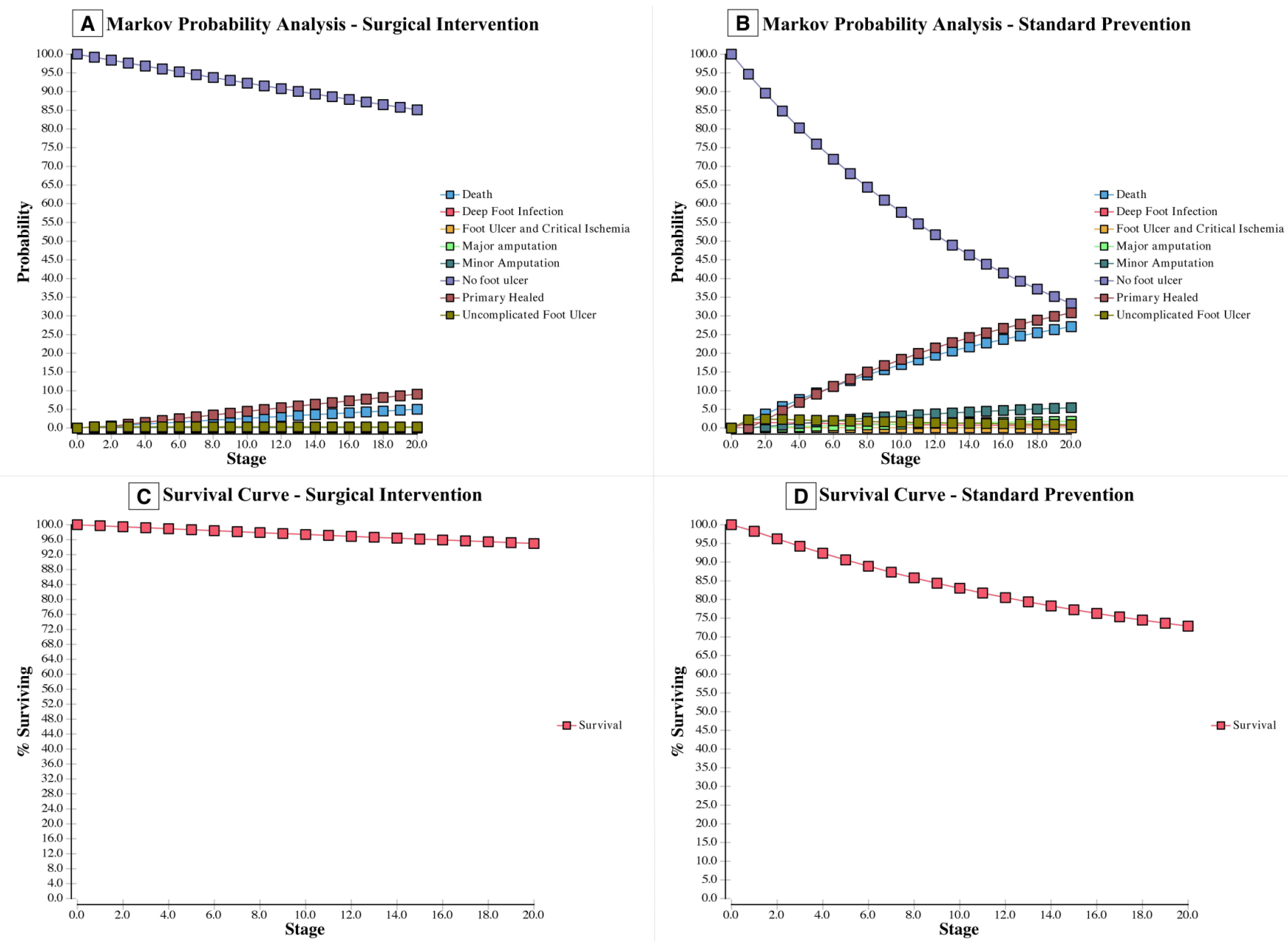

Figure 2 Trends observed over a 10-year simulation period (20 6-month stages) showing a considerably higher probability of preventing foot ulcers in the surgical intervention strategy (A) compared with the standard prevention group (B). Amputations and mortality are also lower for patients undergoing surgery. Estimated survival curves show the impact of reduced mortality with the surgical intervention strategy (C) compared with standard prevention (D).

\section{DISCUSSION}

The results obtained from our model suggest that surgery is a more effective strategy in patients with diabetic sensory neuropathy identified by symptoms and neurosensory testing. Surgery prevented more ulcers and amputations even when the effectiveness of this intervention was set to a minimum of $25 \%$. In all our analyses, surgery while more costly - generated more QALYs and would be considered cost-effective and a candidate for broader adoption based on both clinical and economic criteria. The results are consistent with the tradeoffs that emerge from a technology that costs more to implement but

Table 4 Results of a Monte Carlo analysis consisting of 1000 samples for a PSA and a microsimulation with 1000 random 'walks'

\begin{tabular}{|c|c|c|c|c|c|}
\hline Strategy & Mean & SD & Median & Minimum & Maximum \\
\hline Eff medical & 4.28 & 0.06 & 4.28 & 4.11 & 4.46 \\
\hline Eff surgery & 5.95 & 0.03 & 5.95 & 5.84 & 6.06 \\
\hline Cost surgery & $\$ 35018.82$ & $\$ 203.36$ & $\$ 35025.34$ & $\$ 34362.65$ & $\$ 35674.65$ \\
\hline NMB medical & $\$ 415423.54$ & $\$ 5821.32$ & $\$ 415406.70$ & $\$ 399073.03$ & $\$ 433629.45$ \\
\hline
\end{tabular}

Costs in US\$.

Eff, effectiveness, measured in QALYs; NMB, net monetary benefit with a willingness-to-pay set to $\$ 100000$; PSA, probabilistic sensitivity analysis. 
brings about greater long-run benefits. The key question is whether the results would continue even longer than the 10 years modelled and the value of a QALY.

The costs associated with the surgical intervention and physician follow-up for a single individual are small in contrast to the amount of expenditures related to hospitalisations for ulcer treatments and surgical amputations, the cost of long-term pain medications and other related costs. With the number of complications averted by the surgical intervention, the long-term NMB are superior to those obtained with the current prevention strategy. ${ }^{28}$

\section{Model assumptions}

It is important to note that this model makes several assumptions. First, the model assumes that a foot ulcer precedes all amputations. Also, after healing from an ulcer, the low-risk group patients had the same probability of experiencing a new ulcer as a high-risk group patient and therefore, it was then assumed that prevention was to be the same as the high-risk group. ${ }^{14}$ In addition, it was assumed that an individual could only experience one ulcer per year and that patients with a major amputation could only remain in that state or proceed to death. ${ }^{14}$ Finally, in the baseline analysis, surgical prevention was assumed to reduce the incidence of both foot ulcers and amputations by $80 \%$.

\section{Limitations}

There are some limitations in this study that warrant discussion. With every model simulation, there is uncertainty and this model was simplified in ways that may have influenced the results that were obtained. Furthermore, the model was limited to only 5 years for the baseline simulations and 10 years for the cohort-level simulations. Additionally, it did not follow the patients until they were all deceased.

The probabilities used in this study were derived from a Swedish population. Sweden is a more homogeneous society with public funding and delivery of healthcare services. These are factors that influence health outcomes to a great extent. ${ }^{29}$ Therefore, these probabilities may not be applicable in countries like the USA that have a significantly higher variability in terms of race, access to health services and costs. Additionally, the data ${ }^{14}$ from which these probabilities were garnered date to 2001, and probabilities may have changed as a result of changes in the epidemiology and technology since.

While this study reports a reference case analysis based on a healthcare sector perspective and another reference case analysis based on a societal perspective, it does so only from a formal healthcare point of view. Thus, it excludes indirect healthcare costs such as patient time costs, unpaid caregiver time costs and transportation. Similarly, information such as costs to employers, the government and other segments of society have been omitted. Therefore, while useful in healthcare settings, this information cannot be used to make decisions about the broad allocation of resources across the entire population. ${ }^{30}{ }^{31}$ Using a broader societal perspective would allow us to more accurately determine how much an individual or society would be willing to pay for an additional QALY among patients with diabetes.

\section{CONCLUSIONS}

Diabetes is a disease with many potential complications that result in a substantial health burden and high costs for society. Diabetic neuropathy is one such complication that in addition to high costs of care, it can have a serious impact on a patient's quality of life. The results of this study would indicate that a surgical intervention that decreases the incidence of diabetic foot ulcers and lower extremity amputations is a cost-effective strategy for patients with diabetes plus sensory neuropathy identified by symptoms and neurosensory testing. Patients who undergo tibial neurolysis experience a significant improvement in their quality of life that offsets the extra cost of surgery in the long run. We can thus conclude that among patients with diabetic neuropathy, surgery is likely to be more effective at preventing serious comorbidities and to be associated with a higher survival over time. In our model, surgery also generated greater economic benefits. Knowing the long-term implications on related morbidities and the effect on mortality, patients may be better equipped to make an informed decision about which strategy to choose.

Acknowledgements The abstract for this study was presented and published as follows: Sarmiento S, Pierre J, Dellon AL, Frick K. Tibial Nerve Decompression for the Prevention of the Diabetic Foot: A Cost-Utility Analysis Using Markov Model Simulations. Plast Reconstr Surg Glob Open. 2018 Apr; 6(4 Suppl): 13-14.

Contributors SS: Conceived the idea, designed the study, performed the main statistical analysis and wrote the manuscript. JAP: Contributed to the study design, performed the initial statistical analysis and drafted the manuscript. ALD: Conceived the idea and contributed to the manuscript. KDF: Contributed to the study design, provided guidance throughout this research and provided critical feedback about the results and manuscript.

Funding The authors have not declared a specific grant for this research from any funding agency in the public, commercial or not-for-profit sectors.

Competing interests None declared.

Patient consent for publication Not required.

Ethics approval This health economics study is exempt from IRB review. This study conforms to the Declaration of Helsinki ethical principles for medical research.

Provenance and peer review Not commissioned; externally peer reviewed.

Data sharing statement Extra data can be accessed via the Dryad data repository at https://datadryad.org/resource/doi:10.5061/dryad.485b1c3.

Open access This is an open access article distributed in accordance with the Creative Commons Attribution Non Commercial (CC BY-NC 4.0) license, which permits others to distribute, remix, adapt, build upon this work non-commercially, and license their derivative works on different terms, provided the original work is properly cited, appropriate credit is given, any changes made indicated, and the use is non-commercial. See: http://creativecommons.org/licenses/by-nc/4.0/.

\section{REFERENCES}

1. Centers for Disease Control and Prevention. National Diabetes Statistics Report: Estimates of Diabetes and Its Burden in the United 
States. Atlanta, GA: U.S. Department of Health and Human Services, 2014.

2. World Health Organization. Global report on diabetes. 2016. http:// apps.who.int/iris/bitstream/10665/204871/1/9789241565257_eng. pdf (Accessed 25 Apr 2017).

3. World Health Organization. Diabetes Fact Sheet. 2016. http://www. who.int/mediacentre/factsheets/fs312/en/ (Accessed April 20, 2017).

4. U.S. Department of Health and Human Services, Centers for Disease Control and Prevention. National Diabetes Fact Sheet: National Estimates and General Information on Diabetes and Prediabetes in the United States. 2014. http://www.cdc.gov/diabetes/pubs/pdf/ ndfs_2014.pdf (Accessed 20 Apr 2017).

5. Gonzalez ER, Oley MA. The management of lower-extremity diabetic ulcers. Manag Care Interface 2000;13:80-7.

6. Gordois A, Scuffham P, Shearer A, et al. The health care costs of diabetic peripheral neuropathy in the US. Diabetes Care 2003;26:1790-5.

7. Ragnarson Tennvall G, Apelqvist J. Health-economic consequences of diabetic foot lesions. Clin Infect Dis 2004;39:S132-9.

8. Dellon AL. The Dellon approach to neurolysis in the neuropathy patient with chronic nerve compression. Handchir Mikrochir Plast Chir 2008;40:351-60.

9. Johnson BF, Evans L, Drury R, et al. Surgery for limb threatening ischaemia: a reappraisal of the costs and benefits. Eur $J$ Vasc Endovasc Surg 1995;9:181-8.

10. Baltodano PA, Basdag B, Bailey CR, et al. The positive effect of neurolysis on diabetic patients with compressed nerves of the lower extremities: a systematic review and meta-analysis. Plast Reconstr Surg Glob Open 2013;1:e24.

11. Dellon AL. The four medial ankle tunnels: a critical review of perceptions of tarsal tunnel syndrome and neuropathy. Neurosurg Clin N Am 2008;19:629-48. vii.

12. Dellon AL, Muse VL, Nickerson DS, et al. Prevention of ulceration, amputation, and reduction of hospitalization: outcomes of a prospective multicenter trial of tibial neurolysis in patients with diabetic neuropathy. J Reconstr Microsurg 2012;28:241-6.

13. Centers for Medicare \& Medicaid Services. Medicare's coverage of diabetes supplies \& services. 2016. https://www.medicare.gov/ Pubs/pdf/11022-Medicare-Diabetes-Coverage.pdf (Accessed 25 Apr 2017).

14. Ragnarson Tennvall G, Apelqvist J. Prevention of diabetes-related foot ulcers and amputations: a cost-utility analysis based on Markov model simulations. Diabetologia 2001;44:2077-87.

15. Hjelm K, Apelqvist J, Nyberg P, et al. Health, health care utilization and living conditions in foreign-born diabetic patients in southern Sweden. J Intern Med 1997;242:131-41.

16. International Working Group on the Diabetic Foot: International Consensus on the Diabetic Foot, 2015.
17. Rauner MS, Heidenberger K, Pesendorfer EM. Using a Markov Model to Evaluate the Cost Effectiveness of Diabetic Foot Prevention Strategies in Austria. The Society of Computer Simulation International 2004:63-8.

18. Medicare Benefits Policy Manual (IOM 100-02). Therapeutic Shoes for Individuals with Diabetes. Chapter 15, Section 14, Rev. 228. 2016. https://www.cms.gov/Regulations-and-Guidance/Guidance/ Manuals/downloads/bp102c15.pdf (Accessed 20 Apr 2017).

19. Centers for Medicare \& Medicaid Services. Medicare Claims Processing Manual, Chapter 32-Billing Requirements for Special Services. 2005. http://www.cms.gov/Regulations-and-Guidance/ Guidance/Transmittals/downloads/r498cp.pdf (Accessed $25 \mathrm{Apr}$ 2017).

20. Blue Cross and Blue Shield of Alabama. Understanding facility and non-facility pricing (site of service differential). 2010. https://www. bcbsal.org/providers/newPaymentMethodology/understandingFacilit yAndNonFacilityPricing.pdf (Accessed 25 Apr 2017).

21. Macario $\mathrm{A}$. What does one minute of operating room time cost? $\mathrm{J}$ Clin Anesth 2010;22:233-6.

22. Centers for Medicare \& Medicaid Services. Medicare physician fee schedule. https://www.cms.gov/apps/physician-fee-schedule/ (Accessed 10 May 2017).

23. Rinkel WD, Luiten J, van Dongen J, et al. In-hospital costs of diabetic foot disease treated by a multidisciplinary foot team. Diabetes Res Clin Pract 2017;132:68-78.

24. CPI Inflation Calculator. Bureau of Labor Statistics, US Department of Labor. http://www.bls.gov/data/inflation_calculator.htm (Accessed 10 May 2017).

25. Lipsky BA. Medical treatment of diabetic foot infections. Clin Infect Dis 2004;39 Suppl 2:S104-14.

26. Quality of life in type 2 diabetic patients is affected by complications but not by intensive policies to improve blood glucose or blood pressure control (UKPDS 37). U.K. Prospective Diabetes Study Group. Diabetes Care 1999;22:1125-36.

27. Ragnarson Tennvall G, Apelqvist J. Health-related quality of life in patients with diabetes mellitus and foot ulcers. $J$ Diabetes Complications 2000;14:235-41.

28. Barrett EJ. 2004 presidential address: the sheep, the ostrich, the ant, diabetes, and the tragedy of the common. Diabetes Care 2004;27:3005-8.

29. Osborn R, Squires D, Doty MM, et al. In new survey of eleven countries, us adults still struggle with access to and affordability of health care. Health Aff 2016;35:2327-36.

30. Sanders GD, Neumann PJ, Basu A, et al. Recommendations for Conduct, Methodological Practices, and Reporting of Costeffectiveness Analyses: Second Panel on Cost-Effectiveness in Health and Medicine. JAMA 2016;316:1093-103.

31. Neumann PJ, Weinstein MC. Legislating against use of costeffectiveness information. N Engl J Med 2010;363:1495-7. 